smoghli_otlichit_konsultatsiiu_iskusstviennogho_intielliekta_ot_assistienta_profiessora (access date: 12.06 .2017$)$. (In Russ.).

Svas'ian, K. A. (1987) Fenomenologicheskoe poznanie. Erevan, Izd-vo AN Armianskoi ASSR. 199 p. (In Russ.).

Fedotova, V. G. (2000) Informatsionnoe obshchestvo i knigi dlia elit i mass. In: Obshchestvo i kniga: Ot Gutenberga do Interneta / ed. by A. P. Koroleva. Moscow, Traditsiia. 279 p. Pp. 222-234. (In Russ.).

Fridman, Dzh. (2011) Sleduiushchie 10 let : transl. from Engl. Moscow, Eksmo. 320 p. (In Russ.).

Fuko, M. (1996) Volia k istine: po tu storonu znaniia, vlasti i seksual'nosti. Raboty raznykh let : transl. from Fr. Moscow, Kastal'. 448 p. (In Russ.).

McLuhan, M. (1967) The Guttenberg Galaxy: The Making of Typographic Man. Toronto.

McLuhan, M., Hutchon, K. and McLuhan, E. (1977) City as Classroom: Understanding Language and Media. The Book Society of Canada Limited.

Robertson, R. (1992) Globalization: Social Theory and Global Culture. SAGE. 211 p.

Submission date: 15.05 .2017$.

Костина Анна Владимировна - доктор философских наук, доктор культурологии, профессор, заведующий кафедрой философии, культурологии и политологии, декан факультета культуры и искусства Московского гуманитарного университета. Адрес: 111395, Россия, г. Москва, ул. Юности, д. 5. Тел.: +7 (499) 374-61-81. Эл. адрес: Anna_Kostina @inbox.ru

Kostina Anna Vladimirovna, Doctor of Philosophy, Doctor of Culturology, Professor, Head, Department of Philosophy, Culturology and Politology; Dean, Faculty of Culture and Arts, Moscow University for the Humanities. Postal address: 5, Yunosti St., Moscow, Russian Federation 111395. Tel.: +7 (499) 374-61-81. E-mail: Anna_Kostina @inbox.ru

DOI10.17805/zpu.2017.4.9

\title{
Интерпретация смысла истории: событие как культурный артефакт
}

\author{
А. Я. ФЛИЕР \\ РОССИЙСКИЙ НАУЧНО-ИССЛЕДОВАТЕЛЬСКИЙ ИНСТИТУТ КУЛЬТУРНОГО \\ И ПРИРОДНОГО НАСЛЕДИЯ ИМ. Д. С. ЛИХАЧЕВА
}

В статье разворачивается авторская гипотеза о том, что все исторические события являются, по существу, культурными артефактами и могут быть исследованы и реинтерпретированы культурологией в соответствующем ракурсе (параллельно с собственно историческим анализом), что позволит глубже и полнее понять культурную обусловленность социальной активности человека и детерминированность его поведения культурным контекстом. В этом заключаются практическая актуальность и научная новизна статьи.

Событийная история исследует в основном динамические события социальной реальности и дает им по возможности рациональные объяснения, а антропология истории исследует устойчивые исторические состояния, т. е., по существу, культуру данного общества, и дает им объяснения, основанные на культурно-архетипических проявлениях общественного сознания. Это проявления культурной изменчивости и культурной устойчивости исторической культуры данного общества.

Культурная детерминированность этих событий/артефактов связана с тем, что на вызовы истории каждый народ отвечает по-своему, в соответствии с установками своей локаль- 
ной культуры, своего исторического опыта. Но помимо рациональных оснований в таких ответах большую роль играют и иррациональные соображения, заложенные в архетипическую ткань национальной культуры.

Исследования проблемы «человек в истории» в ракурсе «человек в культуре» позволит гораздо глубже и более основательно проанализировать причинно-следственные основания тех или иных исторических событий.

Ключевые слова: культура; история; динамика культуры; изменчивость культуры; социальная обусловленность культуры; культурная обусловленность; социальная активность человека; символика; традиция; мотивация; обычаи; идеология; мода

\section{BВЕАЕНИЕ}

$\mathrm{H}$ а протяжении более 30 лет, что я занимаюсь культурологическими исследованиями, я постоянно обращаюсь к теме истории и культуры, анализируя разные аспекты их сочетания и взаимодействия (можно назвать работы последних лет (Флиер, 2014, 2015b, 2016a), а также энциклопедию, включающую 85 моих статей (см.: Флиер, 2015a)). Сейчас я хотел бы обратиться к проблеме, суть которой я формулирую таким образом: из чего состоит история, что является ее основными «строительными кирпичами», из которых складывается здание истории того или иного локального сообщества (народа)?

Я полагаю, что такими «кирпичами» являются артефакты культуры соответствующего народа, стихийная и вместе с тем латентно системная совокупность которых и составляет историю этого народа. Здесь вспоминается популярная в свое время дискуссия в среде историков о «событийной и бессобытийной истории» (об этом см., например: $\Lambda$ Г Гофф, 2002). Если первую безоговорочно считали собственно историей предметом исторической науки, то вторую называли «исторической антропологией», поскольку здесь речь шла не о событиях, в той или иной мере меняющих наблюдаемую ситуацию, а, наоборот, об устойчивых состояниях сообщества и его социального сознания. То есть, по существу, историческая антропология описывает в первую очередь культуру данного сообщества, которая рассматривается как «бессобытийная история». Но и событийная история состоит из культурных артефактов, только другого рода. «Бессобытийная история» формируется артефактами культурной устойчивости (как правило, традициями), воспроизводящими из поколения в поколение канонические обычаи, нравы, ценностные установки сознания и т. п. А событийная история - это совокупность артефактов культурной изменчивости, т. е. каких-либо обновлений в социальном устроении сообщества, номенклатуре производимых им продуктов, ценностных установках сознания, художественных стилях и т. п., что, как правило, связано с какими-то внешними вызовами, изменением условий существования сообщества (об этом см., например: Флиер, 2016b). И то и другое в совокупности и формирует тот феномен, который принято называть словом «история».

\section{ЕАИНСТВО ОБЪЕКТА ИСТОРИЧЕСКОЙ НАУКИ И КУАЬТУРОАОГИ}

Гипотеза данной статьи заключается в том, что историческая наука и культурология исследуют один тот же объект, называемый историческими событиями или культурными артефактами, но представляющий собой единый набор феноменов, только по-разному систематизируемых и интерпретируемых. Эти феномены воплощаются в культурно мотивируемых и культурно регулируемых формах, таких как:

- продукты человеческой деятельности (материальные, интеллектуальные, художественные, организационные и пр.); 
- процессы и технологии жизнедеятельности;

- акты индивидуального и группового поведения;

- процедуры взаимодействия и коммуницирования (обычаи и нравы, языки и системы письменности);

- системы верований, представлений и мировоззрения;

- ценности, идеалы и целеустановки;

- художественное творчество;

- образы социальной престижности и т. п.;

Перечень, разумеется, далеко не полный.

В разных социальных типах культуры доминирует своя система обусловленности культурных предпочтений тех или иных форм: в традиционной культуре они диктуются в основном обычаями, в специализированной культуре - политической или религиозной идеологией, в массовой культуре - модой (т. е. системой актуальных образцов социальной престижности). Однако любые социально значимые акты деятельности, поведения, взаимодействий и коммуницирования людей всегда культурно мотивированны и культурно регулируются обществом. В истории иных проявлений социальной активности людей не бывает.

А это означает, что все известные науке факты социальной активности людей могут быть подвергнуты культурологическому анализу (реинтерпретации) на предмет выявления их культурно-ценностной обусловленности. Это как минимум поможет глубже и более точно понять их мотивацию (в контексте ценностных установок изучаемой эпохи и локальной культурной системы), социальную значимость, идеологическую актуальность для своего времени.

Каким образом возникает эта культурная детерминированность исторического события? Аумаю, что вслед за А. Тойнби мы можем разделить событие на некий вызов, порождающий потребность в ответе, и собственно ответ (адаптацию) сообщества на этот вызов (см.: Тойнби, 1991). Вызов может иметь как внешний характер (например, нападение врагов или климатическая катастрофа), так и быть результатом внутреннего развития (появление новых технологий выполнения чего-либо). Но на разные вызовы разные народы отвечают по-разному; одни борются, другие мигрируют, третьи что-то изобретают и т. п. То есть либо адаптируются к изменившимся условиям обитания в этой среде, либо меняют саму среду. Вот этот ответ и детерминируется особенностями культуры данного народа, его историческим опытом, спецификой национального характера. Вызовы могут иметь не глобальный характер, а сколь угодно локальный, касающийся жизни одной семьи, одного крестьянского хозяйства, но всегда ответ на него обусловлен особенностями культуры данного народа. Так события (ответы на вызовы) обретают свою культурную обусловленность.

Моя общая концепция понимания проблемы «человек в истории» заключается в том, что помимо рациональных объяснений человеческой деятельности, предлагаемых исторической наукой, социальная активность человека в большой мере детерминируется и иррациональными культурными установками его сознания, которые исследуются культурологией. Необходимо выстроить основания для более полного и глубокого раскрытия и понимания экстраутилитарных мотиваций и стимулов социальной активности человека в истории, разработать методы анализа культурного контекста такого поведения и мироощущения, идейной и ценностной детерминированности форм и смыслов жизнедеятельности человека в сообществах разных типов и в разные эпохи. Таким образом, понимание прошлого в аспекте «человек в истории» 
получит существенное обновление и радикально углубится за счет познавательных ресурсов культурологии.

\section{АКТУААЬНЫЕ НАПРАВАЕНИЯ ИЗУЧЕНИЯ ПРОБАЕМЫ «ЧЕАОВЕК В ИСТОРИИ》}

Современные исследования проблемы «человек в истории» можно разделить на собственно исторические и культурологические. В исторической науке уже с 30 -х годов XX в. большим авторитетом пользуется программа изучения «человеческого фактора» в истории, являющаяся сейчас одним из основных направлений исторической науки и реализуемая в работе таких научных школ, как «Школа Анналов» (см.,

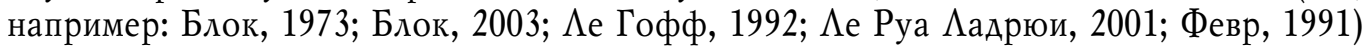
и «Антропология истории» (см., например: Бессмертный, 1991; Гинсбург, 2000; Гуревич, 1981; Гуревич, 1984; Земон Аэвис, 1990; Кром, 2010). Однако эти направления ограничивают себя только познавательными задачами исторической науки - поиском новых рациональных причин и объяснений исторических событий. Теперь же становятся актуальными и иные познавательные задачи: анализ культурной обусловленности социальной активности человека в истории, что относится уже к сфере компетенции культурологии. Культурологических исследований данной проблемы сравнительно немного (Мурье, 2004; Назаретян, 2008; Пелипенко, 2007, 2012; Флиер, 2012 ). Следует сказать, что культурологи и психологи уделяют проблеме «человек в истории» не так много внимания, хотя большинство их отчетливо понимают, что это и есть проблема «человек в культуре», только осмысленная в ином ракурсе.

И в исторических, и в культурологических исследованиях, посвященных теме человека в истории, содержится значительный фактологический материал по мотивации социальной активности человека, но его теоретические обобщения, как правило, ограничиваются культурой конкретного сообщества в конкретную эпоху. Теоретическое обобщение этого материала в масштабе всей истории осуществлял М. С. Каган (Каган, 2001), но он очень мало касался проблем культурной мотивации человеческого поведения, сосредоточиваясь в основном на событиях общесоциальной значимости.

В стремлении теоретически обозначить основные аспекты человеческой жизни и деятельности, в которых социальная активность человека наиболее обусловлена его культурными установками, ценностными ориентациями, стереотипами сознания и т. п., я выделяю две основные проблемы:

- культурные формы исторического бытия человека, сосредоточиваемые на анализе культурной значимости типовых исторических форм социальной активности человека, формировании и развитии ценностных ориентаций и предпочтений исторических сообществ, и

- культурные смысль исторического бытия человека, сосредоточиваемые на реконструкции уже забытых смыслов различных аспектов взаимодействия и социальной коммуникации людей, анализе значимости этих смыслов в господствующей идеологии своего времени.

Культурные формы в основном отображают адаптивную изменчивость приемов и способов жизнедеятельности людей, производство продуктов (не только материальных, но и интеллектуальных, художественных, социальных форм организации, законов, правил и т. п.), более соответствующих изменившимся условиям бытия. Культурные же смыслы, наоборот, детерминируются устойчивостью стереотипов сознания членов сообщества, их приверженностью к традициям, историческим обычаям. 
Эти привычные культурные смыслы своих действий мы часто не замечаем. Мало кто задумывается над тем, почему, здороваясь, мужчины пожимают друг другу правую руку, почему в знак уважения к собеседнику мы снимаем шляпу, почему женщина, держа мужчину под руку, идет слева от него и т. п. А ведь все это имеет определенный культурный смысл, о котором сейчас мало кто вспоминает.

Если с культурной обусловленностью конкретных исторических событий все более или менее ясно, то встает вопрос, насколько можно считать культурным артефактом всю историю какого-либо народа, как некую системную колдизию. Ну, во-первых, всю историю какого-либо народа мы не знаем. Аля этого нужно знать историю жизни каждого человека, всех людей, составлявших в прошлом и составляющих ныне этот народ. Наука создает системное знание лишь о наиболее значимых социальных событиях этой истории, затрагивающих судьбы большинства. Тенденция изучения «человека в истории» как раз и является попыткой выйти за рамки этих ограничений наиболее значимыми событиями и приблизиться к реакции на них рядового человека.

Что же обеспечивает системность этого исторического процесса? Опять-таки культура. Каждый исторический народ по-своему реагирует на те или иные внешние и внутренние вызовы, и специфическое единообразие этим реакциям придает национальный характер народа, т. е. особенности его культуры. Тут, конечно, нужно помнить, что культура каждого народа, а стало быть, и его национальный характер формировались в ходе истории. Но спор о первичности истории или культуры подобен спору о первичности курицы или яйца. И история, и культура всякого народа в своем временном развитии теснейшим образом связаны и постоянно влияют друг на друга. История влияет на содержание культуры, а культура - на формы истории. Аля нас же важно понимание того, что системность истории всякого народа порождает именно его культура (в данном случае выраженная в специфике реакции народа на внешние вызовы).

В целом я полагаю, что культурная обусловленность истории любого народа как системного феномена даже выше, чем отдельного исторического события. Это хорошо видно в наши дни, когда мы постоянно наблюдаем неудачи во внедрении принципов европейской демократии в практику народов Востока (за исключением «Запада на Востоке» - Японии и Южной Кореи), культура которых ориентирована на другое социальное устроение, другой тип власти, другую степень индивидуальной свободы и т. п.

Столь же показательным примером культурной обусловленности истории является идеология. Идеология как ничто иное влияет на политику светских и церковных властей, на господствующую этику и эстетику и даже на повседневное поведение рядовых людей (см. об этом, например: Флиер, 2017). Вместе с тем идеология, будучи в определенном смысле мифологией власти, является самоочевидным продуктом идейно-ценностных установок культуры и внедряется в сознание населения (в первую очередь в его историческое сознание) как культурная программа социально одобряемого поведения и суждений о социальной реальности.

Слово «история» имеет два смысла: во-первых, хронологическую последовательность событий социальной реальности и, во-вторых, чей-то систематизированный рассказ об этой последовательности, нарратив (об этом см., например: Никонова, 2011). Первую историю (реальную) в какой-то мере знают профессиональные историки, археологи, антропологи. Массовый обыватель знает в основном лишь вторую историю (нарратив). Но если и реальные события истории в той или иной мере культур- 
но обусловлены, то уж нарративный рассказ о них тем более детерминирован какойто идеологией, которой ангажирован сам рассказчик. Такая ангажированность может иметь как осмысленный характер (когда сам историк является адептом какого-то политического или интеллектуального учения) или же быть латентной, поскольку любой историк обладает каким-то системным мировоззрением, хотя не всегда рефлексирует это.

Вопрос об избавлении исторической науки от подобной политической ангажированности и превращении ее в беспристрастное объективное знание является одним из древнейших в профессиональной саморефлексии историков. Но какого-либо положительного решения он так и не находит. Я убежден, что столь же ангажирована и научная позиция культурологов; просто в культурологии эта проблема еще не стала практически актуальной (культурология меньше, чем историческая наука, используется как инструмент патриотического воспитания). Но когда-нибудь обязательно станет. Так что культурная обусловленность всякого знания об истории актуальна вдвойне.

\section{ОСОБЕННОСТИ КУАБТУРНОЙ ОБУСАОВАЕННОСТИ ИСТОРИИ}

Возникает вопрос: а возможна ли история без культуры? Аумаю, что нет. Ведь история - это человеческая деятельность, а также наша попытка системно описать эту деятельность в хронологической последовательности. Но любая человеческая деятельность в большей или меньшей степени культурно детерминирована. По этому признаку она и является собственно человеческой. Тем более культурно детерминировано любое ее описание. Следовательно, история без культуры - это уже какая-то иная история, в основе которой лежит не человеческая деятельность. Иное дело, каким образом человеческую деятельность описывать и объяснять. Историческая наука делает это с акцентом на ее рационально-адаптивные детерминанты, культурологию больше интересуют ее идеально-ценностные основания.

Вместе с тем, интерпретируя историю как культурный артефакт, следует избегать опасности сведения всей истории к исполнению запрограммированных культурных установок. История - это игра без правил. Во всяком случае, еще никому не удавалось составить подтверждаемый социальными реалиями систематический свод таких правил. Иллюстрацией тому может служить крах марксистской историософии с ее претензией на раскрытие этих правил, хотя она создавалась очень компетентными специалистами, и в менее глобальном масштабе (не историческом, а социальном) марксизм может применяться как одна из методологий социального анализа.

Так или иначе, но каждый новый вызов истории или природы требует «придумывания на ходу» более или менее импровизационного ответа. Аругое дело, что всякое осмысленное и социально значимое действие человека отчасти является таким «придумыванием на ходу», а отчасти регулируется имеющимся социальным опытом, т. е. культурой. И даже в глубокой первобытности, когда, казалось, вся жизнь состояла из досконального повторения культурного опыта предков, какая-то адаптивная импровизация все-таки имела место. Иначе бы мы до сих пор пользовались каменными топорами. Впрочем, и топоры нужно было в какой-то момент и в какой-то ситуации изобрести. Так что традиция и инновация (опыт и адаптация) всегда были рядом и фактически не могут существовать друг без друга.

Ну и наконец, последний вопрос: чем отличается изложение истории культуры от изложения всеобщей (условно говоря, гражданской) истории? Я думаю, что структур- 
но ничем. Просто в интерпретации тех или иных событий и ситуаций акцент переносится с описания их рациональных причин (вызовов) на описание культурных установок сознания соответствующего народа (социальной группы), определяющих специфику его реакции на эти вызовы. Например, в событиях Варфоломеевской ночи во Франции, вылившихся в стихийную массовую резню гугенотов (неожиданную даже Аля политической власти, совершенно не планировавшей такой масштаб убийств и даже пытавшейся как-то локализовать его), решающую роль сыграло то, что дело происходило в большом городе, где масса лавочников воспользовалась возможностью безнаказанно пограбить. В деревне среди крестьян, еще более фанатичных католиков, но обладавших совершенно иной ментальностью и отношением к собственности, масштаб событий был бы совсем иным. Так что историк, говоря о Варфоломеевской ночи, будет делать акцент на политических причинах события, а культуролога будут больше интересовать психолого-ментальные установки участников.

Аругой пример: Пугачевский бунт. Навряд ли большинство сподвижников Пугачева верили в то, что он император Петр III. Но здесь важна была идеологическая установка восставших на то, что они бунтуют не против царя, а в поддержку «подлинного» царя. Историка в Пугачевском бунте будет больше интересовать реакция крестьянства на полное закрепощение, а культуролога - его ментальные стереотипы, привязанность к символике «правильного» царя.

\section{ЗАКАЮЧЕНИЕ}

Таким образом, я еще раз подчеркиваю свою основную мысль. Историческая наука и культурология исследуют единый объект - формы и результаты (продукты) человеческой деятельности прошлого и настоящего, в той или иной мере культурно детерминированные, а также их смыслы и системный характер их совокупности. В исторической науке, делающей акцент на рациональной обусловленности описываемых феноменов, они называются историческими событиями, а в культурологии, акцентирующей идеально-ценностную обусловленность подобных явлений, они называются культурными артефактами. Но, по существу, исследуется единый феномен деятельности и ее результатов, описываемый в разных интерпретациях. Поэтому весь фактурный материал, накопленный исторической наукой и ее специализированными подразделами (археологией, антропологией, искусствознанием), может и должен подвергнуться реинтерпретации с позиций культурологии, что приведет к существенному расширению наших знаний о социальной реальности пошлого и настоящего. Культурная обусловленность поведения «человека в истории» есть то же самое, что и социально-контекстуальная обусловленность поведения «человека в культуре». Историческая и культурологическая интерпретации событий/артефактов должны органично дополнять друг друга.

\section{СПИСОК АИТЕРАТУРЫ}

Бессмертный, Ю. А. (1991) Жизнь и смерть в средние века. Очерки демографической истории Франции. М. : Наука. 240 с.

Блок, М. (1973) Апология истории, или Ремесло историка. М. : Наука. 236 с.

Блок, М. (2003) Феодальное общество. М. : Изд-во им. Сабашниковых. 503 с.

Гинсбург, К. (2000) Сыр и черви. Картина мира одного мельника, жившего в XVI в. М. : РОССПЭН. 272 с.

Гуревич, А. Я. (1981) Проблемы средневековой народной культуры. М. : Искусство. 359 с.

Гуревич, А. Я. (1984) Категории средневековой культуры. М. : Искусство. 350 с. 
Земон Аэвис, Н. (1990) Возвращение Мартена Герра. М. : Прогресс. 208 с.

Каган, М. С. (2001) Введение в историю мировой культуры : в 2 т. СПб. : Петрополис. $383+320$ c.

Кром, М. М. (2010) Историческая антропология : учеб. пособие. СПб. : Издательство Европейского университета в Санкт-Петербурге. 207 с.

$\Lambda$ е Гофф, Ж. (1992) Цивилизация средневекового Запада. М. : Прогресс. 376 с.

$\Lambda$ е Гофф, Ж. (2002) Аругое средневековье. Время, труд и культура Запада. Екатеринбург : Изд-во Уральского университета. 328 с.

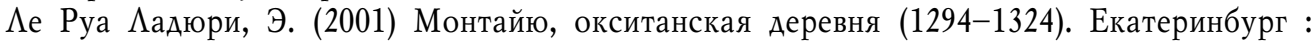
Изд-во Уральского университета. 536 с.

Аурье, С. В. (2004) Историческая этнология : учеб. пособие для вузов. М. : Академический проект: Гаудеамус. 624 с.

Назаретян, А. П. (2008) Антропология насилия и культура самоорганизации. Очерки по эволюционно-исторической психологии. М. : УРСС. 256 с.

Никонова, С. Б. (2011) Нарратив: описание истории или самосознание историка? // Человек. № 2. C. 166-173.

Пелипенко, А. А. (2007) Ауалистическая революция и смыслогенез в истории. М. : МГУКИ. 436 c.

Пелипенко, А. А. (2012) Постижение культуры : в 2 ч. М. : РОССПЭН. Ч. 1. Культура и смысл. 607 с.

Тойнби, А. (1991) Постижение истории. М. : Прогресс. 736 с.

Февр, $\Lambda$. (1991) Бои за историю. М. : Наука. 635 с.

Флиер, А. Я. (2012) Очерки теории исторической динамки культуры. М. : Согласие. 560 с.

Флиер, А. Я. (2014) Теория культуры как философия истории [Электронный ресурс] // Культура культуры. № 1. URL: http://cult-cult.ru/teoriya-kulitury-kak-filosofiya-istorii/ (дата обращения: 22.07.2017).

Флиер, А. Я. (2015а) Историческая культурология как область знания и др. статьи // Историческая культурология / отв. ред. Э. А. Шулепова. М. : Академический проект ; Альма Матер. 795 c.

Флиер, А. Я. (2015b) История как культура и культура как история [Электронный ресурс]// Информационный портал Знание. Понимание. Умение. № 4. URL: http://zpu-journal.ru/e-zpu/ 2015/4/Flier_History-Culture/ (дата обращения: 22.07.2017).

Флиер, А. Я. (2016а) Социальный и исторический аспекты культурной динамики // Вопросы культурологии. № 1. С. 24-33.

Флиер, А. Я. (2016b) Развитие теории исторической динамики культуры: взаимодействие социального и культурного факторов // Знание. Понимание. Умение. №3. С. 109-112. DOI: $10.17805 /$ zpu.2016.3.9

Флиер, А. Я. (2017) Аве роли человека в «спектакле культуры» // Знание. Понимание. Умение. № 1. С. 123-131. DOI: $10.17805 / /$ zpu.2017.1.8

Аата поступления: 04.09.2017 2.

\section{INTERPRETATION OF THE MEANING OF HISTORY: EVENT AS A CULTURAL ARTIFACT \\ A. YA. FLIER \\ RUSSIAN SCIENTIFIC RESEARCH INSTITUTE FOR CULTURAL and NATURAL HeRITAGE NAMED AFTER D. LIKHACHOV}

The article unfolds the author's hypothesis that all historical events are essentially cultural artifacts and can be researched and reinterpreted by culturology in the appropriate perspective (in parallel with the historical analysis proper), which will allow a deeper and fuller understanding of the cultural conditioning of a person's social activity and the determinism of their behaviour by cultural context. This is the practical relevance and scientific novelty of the article. 
Event history explores mainly dynamic events of social reality and gives them rational explanations as much as possible, and the history anthropology explores stable historical states, i. e. in essence, the culture of the given society, and gives them explanations based on cultural-archetypal manifestations of social consciousness. These are manifestations of the cultural variability and cultural stability of the historical culture of a given society.

The cultural determinism of these events / artifacts is related to the fact that each nation responds to its historical challenges in its own way, according to the attitudes of its local culture and its historical experience. But in addition to rational reasons, irrational considerations, embedded in the archetypal fabric of the national culture, play an important role in such answers.

Studies of the issue of «man in history» in the perspective of «man in culture» will allow a much deeper and more thorough analysis of the cause-and-effect reasons for certain historical events.

Keywords: culture; history; dynamics of culture; variability of culture; social conditioning of culture; cultural conditioning; human social activity; symbols; tradition; motivation; customs; ideology; fashion

\section{REFERENCES}

Bessmertnyi, Iu. L. (1991) Zhizn' i smert'v srednie veka. Ocherki demograficheskoi istorii Frantsii. Moscow, Nauka. 240 p. (In Russ.).

Blok, M. (1973) Apologiia istorii, ili Remeslo istorika. Moscow, Nauka. 236 p. (In Russ.).

Blok, M. (2003) Feodal' noe obsbchestvo. Moscow, Izd-vo im. Sabashnikovykh. 503 p. (In Russ.).

Ginsburg, K. (2000) Syr i chervi. Kartina mira odnogo mel'nika, zbivshego v XVI v. Moscow, ROSSPEN. 272 p. (In Russ.). Russ.).

Gurevich, A. Ia. (1981) Problemy srednevekovoi narodnoi kul'tury. Moscow, Iskusstvo. 359 p. (In

Gurevich, A. Ia. (1984) Kategorii srednevekovoi kul'tury. Moscow, Iskusstvo. 350 p. (In Russ.).

Zemon Devis, N. (1990) Vozvrashchenie Martena Gerra. Moscow, Progress. 208 p. (In Russ.).

Kagan, M. S. (2001) Vvedenie v istoriiu mirovoi kul'tury : in 2 vol. St. Petersburg, Petropolis. $383+320$ p. (In Russ.).

Krom, M. M. (2010) Istoricheskaia antropologiia : ucheb. posobie. St. Petersburg, Izdatel'stvo Evropeiskogo universiteta v Sankt-Peterburge. 207 p. (In Russ.).

Le Goff, Zh. (1992) Tsivilizatsiia srednevekovogo Zapada. Moscow, Progress. 376 p. (In Russ.).

Le Goff, Zh. (2002) Drugoe srednevekov' e. Vremia, trud i kul'tura Zapada. Ekaterinburg, Izd-vo Ural'skogo universiteta. 328 p. (In Russ.).

Le Rua Ladiuri, E. (2001) Montaiiu, oksitanskaia derevnia (1294-1324). Ekaterinburg, Izdatel'stvo Ural'skogo universiteta. 536 p. (In Russ.).

Lur'e, S. V. (2004) Istoricheskaia etnologiia : ucheb. posobie dlia vuzov. Moscow, Akademicheskii Proekt, Gaudeamus. 624 p. (In Russ.).

Nazaretian, A. P. (2008) Antropologiia nasiliia i kul'tura samoorganizatsii. Ocherki po evoliutsionno-istoricheskoi psikbologii. Moscow, URSS. 256 p. (In Russ.).

Nikonova, S. B. (2011) Narrativ: opisanie istorii ili samosoznanie istorika? Chelovek, no. 2, pp. 166-173. (In Russ.).

Pelipenko, A. A. (2007) Dualisticheskaia revoliutsiia i smyslogenez v istorii. Moscow, MGUKI. 436 p. (In Russ.).

Pelipenko, A. A. (2012) Postizhenie kul'tury : in 2 vol. Moscow, ROSSPEN. Vol. 1. Kul'tura i smysl. 607 p. (In Russ.).

Toinbi, A. (1991) Postizhenie istorii. Moscow, Progress. 736 p. (In Russ.).

Fevr, L. (1991) Boi za istoriiu. Moscow, Nauka. 635 p. (In Russ.). Russ.).

Flier, A. Ia. (2012) Ocherki teorii istoricheskoi dinamki kul'tury. Moscow, Soglasie. 560 p. (In

Flier, A. Ia. (2014) Teoriia kul'tury kak filosofiia istorii. Kul'tura kul'tury, no. 1 [online] Available at: http://cult-cult.ru/teoriya-kulitury-kak-filosofiya-istorii/ (access date: 22.07.2017). (In Russ.). 
Flier, A. Ia. (2015a) Istoricheskaia kul'turologiia kak oblast' znaniia i dr. stat'i. In: Istoricheskaia kul'turologiia / ed. by E. A. Shulepova. Moscow, Akademicheskii proekt; Al'ma Mater. 795 p. (In Russ.).

Flier, A. Ia. (2015b) Istoriia kak kul'tura i kul'tura kak istoriia. Informatsionnyi portal Znanie. Ponimanie. Umenie, no. 4 [online] Available at: http://zpu-journal.ru/e-zpu/2015/4/Flier_HistoryCulture/ (access date: 22.07.2017). (In Russ.).

Flier, A. Ia. (2016a) Sotsial'nyi i istoricheskii aspekty kul'turnoi dinamiki. Voprosy kul'turologii, no. 1, pp. 24-33. (In Russ.).

Flier, A. Ia. (2016b) Razvitie teorii istoricheskoi dinamiki kul'tury: vzaimodeistvie sotsial'nogo i kul'turnogo faktorov. Znanie. Ponimanie. Umenie, no. 3, pp. 109-112. DOI: 10.17805/zpu.2016.3.9

Flier, A. Ia. (2017) Dve roli cheloveka v «spektakle kul'tury». Znanie. Ponimanie. Umenie, no. 1, pp. 123-131. DOI: $10.17805 / /$ zpu.2017.1.8

Submission date: 04.09.2017.

Флиер Андрей Яковлевич - доктор философских наук, профессор, главный научный сотрудник Российского научно-исследовательского института культурного и природного наследия им. А. С. Аихачева. Адрес: 129366, Россия, г. Москва, ул. Космонавтов, д. 2. Тел.: +7 (495) 686-13-19. Эл. aApec: andrey.flier@yandex.ru

Flier Andrey Yakovlevich, Doctor of Philosophy, Professor, Chief Research Fellow, Russian Scientific Research Institute for Cultural and Natural Heritage named after D. Likhachov. Postal address: 2, Kosmonavtov St., Moscow, Russian Federation 129366. Tel.: +7 (495) 686-13-19. E-mail: andrey. flier@yandex.ru

DOI10.17805/zpu.2017.4.10

\title{
Октябрь 1917: идеология революции
}

\author{
Г. П. ХОРИНА
}

\section{МОСКОВСКИЙ ГУМАНИТАРНЫЙ УНИВЕРСИТЕТ}

Статья посвящена анализу события столетней давности, которое изменило политическую карту мира, - Великой Октябрьской социалистической революции. Автор рассматривает причины и духовные основания социалистической революции, опираясь на труды мыслителей, участников и очевидцев тех событий.

Монархический строй, просуществовавший в России более трех столетий, не сумел ответить на вызовы времени. Слабость и историческую исчерпанность самодержавия показала Русско-японская война, в которой Россия понесла огромные потери, потерпела поражение. Первая русская революция 1905-1907 гг. не ликвидировала самодержавие, практически не решила многие социально-экономические и другие вопросы. В стране не было самолетов, машин, в армии главным средством передвижения был гужевой транспорт; крайне низкой была грамотность населения. Россия как была страной «второго эшелона» капитализма, так и осталась. Эти и другие факторы через десять лет привели к Февральской буржуазно-демократической революции.

Февральская революция 1917 г., либеральная по своей сути, покончила с самодержавием. Россия на короткое время стала самой свободной и демократической страной в мире, но не сумела решить проблемы земли, войны и мира, национальный вопрос. Временное правительство, которое оказалось у руля государственной власти, в силу различных идеологических взглядов не смогло выработать общие цели и задачи, единую тактику по выводу России из системного кризиса. Оно не имело необходимых полномочий для про- 